\title{
The Contradictory Leadership in Orwell's Animal Farm Through Buginese Perspective as Cultural Lesson for Indonesian Language for Foreign Speaker (BIPA) Learner
}

\author{
A Ilah Nurul Falah ${ }^{1}$ \\ ${ }^{1}$ Hasanuddin University, Indonesia, \\ 1.ilafalah001@gmail,com; falahain17@student.unhas.ac.id
}

\begin{abstract}
The number of people who interested to learn Indonesian Language continues to increase. In South Sulawesi there are more than five Language Schools for learning Indonesian Language. Indonesian Language learning has been considered always bundled with culture. Indonesia has around 1300 types of tribes that spread across 34 provinces. Lessons about culture are gained from discussion and directly experienced by the Indonesian language learner. Makassar, South Sulawesi, known to have 3 tribes includes Makassarese, Buginese and Torajanese. Through cultural lesson, Indonesian Language learner could find out how people live their lives according to the philosophy of life that comes from ancestors wrapped in their tribal identity. Moreover the cultural lessons are in learning curriculum. Leadership model is one thing that always associated with the person's philosophy of life where it is very influential with of that person's origin tribe. The researcher analyzed the leadership model that reflected in the novel using Goldman's Genetic Structuralism approach that focuses on the author of the novel. The researcher uses qualitative method both for collecting and analyzing data. The results of this study indicate that there are three leadership values of Buginesse Leadership Model. They are: Lempu means honest and truthful; Getteng means firm and strong on the establishment; and Ada Tongeng means hold fast to the truth. To make it easier to understand by the Indonesian language learner, the researcher is explaining them in contrast with leadership value that is showed in Orwell's Animal Farm.
\end{abstract}

Keywords: Buginese, Foreign, Cultural Lesson, Indonesian Language, Leadership, Lesson Curriculum.

\section{PENDAHULUAN}

Bahasa Indonesia berkembang pesat sejak di tetapkannya menjadi bahasa nasional sejak tahun 1928 silam. Pada Kamus Besar Bahasa Indonesia edisi pertama (1988) hanya memuat perbendaharaan kata sekitar 72.000 lema (entry). Pada edisi kedua (1993) sudah memuat kosakata sebanyak 80.000 lema. Hal ini menunjukkan dalam kurun waktu 5 tahun terdapat penambahan kosakata sebanyak 8.000 lema. Sejak tahun 1993 sampai dengan sekarang (2008 atau sekitar 15 tahun), bahasa Indonesia terus berkembang. Bahkan dalam edisi ketiga, KBBI memuat tidak kurang dari 100.000 lema[3]. Hal ini sejalan dnegan pengaruh bahasa Indonesia 
telah berkembang ke mancanegara. Hingga hari ini bahasa Indonesia telah diajarkan sebagai bahasa kedua (asing) di lebih 75 negara di dunia.

Jumlah pemelajar BIPA semakin meningkat dari tahun ke tahun. Diantara 34 provinsi di Indonesia. Ada beberapa kota besar di Indonesia menjadi tujuan para calon pembelajar yang berminat untuk belajar Bahasa dan Budaya Indonesia. Mackey dan Mountford dalam Suyitno menjelaskan bahwa ada tiga kebutuhan yang mendorong seseorang belajar bahasa, yakni (1) kebutuhan akan pekerjaan, (2) kebutuhan program latihan kejuruan, dan (3) kebutuhan untuk belajar[9]. Pelajaran bahasa selalu diajarkan bersamaan dengan budaya. Seseorang yang belajar bahasa baru tentulah tidak hanya perlu mempelajari tentang struktur kalimat, pengucapan, kosakata dan arti dari kata dalam bahasa tersebut, tapi juga sangat butuh mempelajari tentang budaya orang - orang penutur asli bahasa yang dipelajarinya.

Menurut Suyitno dalam Gajewski (...) orang asing suka mengekpresikan diri mereka, mempresentasikan sesuatu, mengemukakan pendapat, sehingga tugas di luar kelas atau membuat proyek sederhana akan sangat menarik[1]. Melalui tugas sejenis pemelajar akan turun ke masyarakat. Hal - hal yang berkaitan dengan ini biasanya lebih banyak di bahas pada kelas diskusi. Bagaimana seorang pemelajar bipa menempatkan didirnya dalam masyarakat sangat didukung dnegan pengetahuannya tertang budaya masyarakat setempat. Semakin luas pengetahuan budayanya semakin mudah pula pemelajar bipa membawa diri.

Sujana dalam Ryeo menyatakan bahwa sampai saat ini sudah tercatat paling tidak ada 179 sentra penyelenggara pengajaran bahasa Indonesia di 48 negara dan diprediksi akan terus berkembang[8]. Di Makassar, Sulawesi Selatan, Indonesia terdapat 5 sentra penyelenggara pengajaran bahasa Indonesia termasuk Pusat Bahasa milik universitas maupun lembaga swasta yang berdiri sendiri.

Novel berjudul Animal Farm karya George Orwell menjadi salah satu novel yang sangat popular di kalangan orang asing khususnya di benua Amerika. Novel ini menjadi bacaan wajib untuk pelajar setingkat Sekolah Menengah Pertama. Novel ini adalah jenis novel satiris alegori tentang hewan yang melakukan perlawanan pada pemilik peternakan, hingga akhinya mengusir pemilik peternakan. Novel ini juga dianggap sebagai totaliterisme Uni Soviet pada masa Perang Dunia II. Melalui bahan ajar yang meliputi novel Animal Farm dan kepemimpinan menurut perspektif suku Bugis, ini akan enjadi sebuag kebaharuan dan menarik minat para pemelajar.

Bahan ajar BIPA sangat besar manfaatnya bagi program BIPA karena dalam bahan ajar BIPA ranah sosial budaya kita bisa memasukkan kekayaan jati diri, karakter, dan budaya kita sebagai bangsa Indonesia[11]. Ada sekitar 1300 suku yang tersebar dari sabang hingga Merauke. Bagi para pemelajar BIPA yang memilih Makassar sebagai kota tujuan untuk belajar tentunya akan sangat akrab dengan 3 suku besar di Sulawesi selatan. Diantaranya Makassar, Bugis dan Toraja. Filosofi hidup sebuah komunitas tentulah menjadi budaya di komunitas tersebut. Termasuk nilai - nilai kepemimpinan yang dijadikan pegangan bagi orang Bugis, Sulawesi Selatan. Adapun tujuan penelitian ini adalah menjadkan hasil penelitian sebagai media untuk mengenalkan budaya kepada pemeleajar Bahasa Indonesia. Adapun bahasan budayanya menyangkut nilai kepemimpinan yang menjadi tolak ukur pemimpim ideal menurut perspektif suku Bugis dengan melihat pertentangan nilai kepemimpinan yang terkandung dalam novel Animal Farm

\section{METODE PENELITIAN}

Dalam penelitian in, deskriptif kualitatif digunakan sebagai metode penelitian. Dalam proses mengumpulkan data, menggunakan sumber dari (1) Novel Animal Farm; (2) berbagai 
buku tentang BIPA dan tentang Suku Bugis; (3) Berbagai jurnal terkait;. Kemudian, peneliti menggunakan metode penelitian perpustakaan untuk mengumpulkan data pendukung dari beberapa buku, jurnal, artikel dan informasi dari internet yang dianggap berhubungan dengan penelitian ini. Penelitian ini menggnakan analisis deskriptif untuk menganalisis novel. Analisis dilaksanakan berdasarkan langkah-langkah untuk menggambarkan hal-hal yang terjadi dalam novel, seperti konflik antara karakter, plot, dan sebagainya. Untuk menganalisis data, peneliti menggunakan pendekatan strukturalisme genetik milik Lucien Golmann. Peneliti menganalisis unsur intrinsik novel kemudian menguraikan nilai kepemimpinan yang digambarkan oleh penulis dan terdapat dalam novel. Setelah itu mencari tahu tentang nilai kepemimpinan yang ada dalam perspektif suku Bugis. Lalu menganalisis kepemimpinanynag bertentangan anatara novel Animal Farm karya Orwell dengan kepemimpinan menurt perspektif suku Bugis. Hasil dari penelitian ini akan di gunakan sebagai bahan kelas diskusi budaya untuk pemelajar BIPA

\section{HASIL DAN PEMBAHASAN}

Pemerintah juga telah mengeluarkan peraturan tentang hal ini. Peraturan ini tertuang dalam UU No. 24 tahun 2009 tentang Bendera, Bahasa, dan Lambang Negara dan Lagu Kebangsaan. Bahwa pemerintah berkomitmen untuk menginternasionalkan bahasa Indonesia. Langkah nyata saat ini dalam upaya adalah melalui BIPA (Bahasa Indonesia Bagi Penutur Asing). Di mana peserta didik tidak hanya belajar bahasa Indonesia tetapi juga budaya Indonesia. Dengan adanya BIPA diharapkan bahasa dan budaya Indonesia akan menjadi lebih dikenal oleh dunia, dan dapat paralel dengan negara-negara lain yang telah diakui secara internasional[7]. Hal ini sangat berkaitan dengan pebelajaran budaya kepada pemelajar BIPAbaik melalui kelas diskusi ataupun melalui pengalaman saat terjun langsung ke komunitas penutus asli Bahasa Indonesia.

Suparlan dalam Husamah menyatakan kebudayaan dapat didefinisikan juga sebagai suatu keseluruhan pengetahuan manusia sebagai makhluk sosial yang digunakannya untuk memahami dan menginterpretasi lingkungan dan pengalamannya, serta menjadi pedoman bagi tingkah lakunya. Suatu kebudayaan merupakan milik bersama anggota suatu masyarakat atau suatu golongan sosial, yang penyebarannya kepada anggota-anggotanya dan pewarisannya kepada generasi berikutnya dilakukan melalui proses belajar dan dengan menggunakan simbol-simbol yang terwujud dalam bentuk yang terucapkan maupun yang tidak (termasuk juga berbagai peralatan yang dibuat oleh manusia). Dengan demikian, setiap anggota masyarakat mempunyai suatu pengetahuan mengenai kebudayaannya tersebut yang dapat tidak sama dengan anggota-anggota lainnya, disebabkan oleh pengalaman dan proses belajar yang berbeda dan karena lingkungan-lingkungan yang mereka hadapi tidak selamanya sama.[4]

Salah satu masalah dalam belajar bahasa asing adalah adanya kesenjangan antara bahasa pertama dan bahasa target yang akan dipelajari.Hal ini sering terjadi karena kurangnya pengetahuan bahasa target oleh pembelajar bahasa asing. Secara umum dapat dikatakan bahwa semakin jauh kesenjangan itu, semakin sulit proses pembelajarannya; dan semakin dekat kesenjangan itu, semakin mudah proses pembelajarannya.[10] Hal ini menjadi alasan patutnya pelajaran Bahasa dan Budaya Indonesia selalu diajarkan secara bersamaan.

Mustakim dalam Ruskhan menyatakan belum semua buku pengajaran BIPA menyajikan materi yang menyentuh kebudayaan Indonesia. dari 43 buku yang diteliti, terdapat 24 buku (56\%) buku yang menyajikan materi social budaya Indonesia. Hal itu berarti ada 19 buku (44\%) yang belum menyajikan social budaya Indonesia secara optimal. Walaupun begitu, dari 
19 judul itu sebanyak 11 buku tidak menyajikan sama sekali aspek sosial budaya, sedangkan yang lain ada menyinggungnya, tetapi porsinya sangat sedikit.[6] Hal ini menjadi penguat tetap diadakananya kelas diskusi budaya pada lembaga penyelenggara pengajaran BIPA.

Menurut Machmud, ada 3 hal yang dijadikan patokan oleh suku Bugis dalam memilih pemimpin, diantaranya (1) Getteng berarti tegas dan teguh pendirian; (2)Lempu' jika diterjemahkan berdasarkan kata berarti lurus, dalam hal ini lempu' diibaratkan dengan jujur; (3) Ada Tongeng, jika diterjemahkan menurut arti kata, ada berarti perkataan dan tonging berarti benar. Jika ditelurusi ada tonging berarti mengatakan yang benar.

Pada patokan yang pertama, yaitu getting yang berarti tegas, data 1: "Muriel," katanya, "bacakan padaku Perintah Keempat. Apakah itu tidak mengatakan sesuatu tentang tidak pernah tidur tempat tidur?" Dengan susah payah Muriel mengatakannya. "Dikatakan, 'Tidak ada binatang yang tidur di tempat tidur dengan seprei' ' akhirnya dia mengumumkan. Anehnya, Clover tidak ingat itu.[5] Berdasarkan data tersebut terlihat jika beberapa tokoh sebenarnya jika mereka ditipu namun tidak mampu berbuat apa - apa. Mereka merasa terlalu takut dengan ancaman pemimpin mereka, Napoleon.

Pada patokan kedua yaitu Lempu' yang berarti jujur. Kejujuran dianggap sebagai sumber kata-kata yang tegas dan jujur. Ini adalah nilai yang sangat penting tidak hanya di komunitas Bugis tetapi juga di seluruh dunia. Di Silasa oleh Machmud, ada filosofi Bugis, majjekko kandao [4] yang artinya seperti sabit melengkung. Melengkung berarti bentuk yang tidak lurus. Sesuatu yang tidak lurus diartikan tidak jujur. Jadi arti sabit melengkung dalam hal ini adalah untuk menarik sebanyak mungkin keuntungan di sekitarnya. cara yang sama sabit bekerja. Data 3: Tempat tidur hanya berarti tempat tidur. Tumpukan jerami di sebuah kandang adalah tempat tidur, yang dianggap layak. Aturan itu terhadap lembaran, yang merupakan penemuan manusia. Kami telah melepas seprai dari tempat tidur rumah pertanian, dan tidur di antara selimut. Dan tempat tidur yang sangat nyaman juga![5] Jelas sekali terlihat bagaimana tokoh pemimpin beserta anggotanya mencari - cari alasan agar mereka bisa tidak telrihat salah.

Pada patokan ketiga yaitu Ada Tongeng Data 3: Napoleon sangat sadar akan hasil buruk yang mungkin terjadi jika fakta sebenarnya dari situasi makanan diketahui, dan ia memutuskan untuk menggunakan Mr. Whymper untuk menyebarkan kesan yang berlawanan.[5] Dalam hal ini, Napolean sebagai pemimpin tidak benar-benar memiliki nilai jujur. Dia mengatakan banyak kebohongan untuk mendapat manfaat. Untuk menutupi kelemahannya, dia mengatakan kebohongan dan melakukan sesuatu untuk itu. Ini benar-benar bertentangan dengan nilai pemimpin dalam perspektif orang Bugis.

Melalui berbagai budaya yang ada di seluruh Indonesia, para pembelajar asing diajak menggunakan bahasa Indonesia sesuai dengan keperluan masing-masing. Mereka diajak mengenal lebih jauh tentang berbagai acara adat, baik yang berwujud upacara-upacara adat, religi, tradisi, norma, aturan-aturan, maupun hasil karya yang berwujud fisik, seperti candi (seni patung), seni batik, dan sebagainya [12]

Hasil penelitian ini dapat dijadika bahan diskusi dalam kelas budaya pagi pemelajar Bahasa Indonesia [13][14]. Adapun pembahasan yang meliputi kontradiksi antara novel Animal Farm dan kepemimpinan menurt perspektif suku Bugis diharapkan dapat membantu para pemelajar dalam memahami makna yang terkandung dalam kepemimpinan menurut Suku Bugis.

\section{SIMPULAN}


Pembelajaran budaya selalau tidak bisak lepas saat belajar satu bahasa. Ibaratnya budaya dan bahasa sudah menjadi 1 paket dan tidak bisa terpisah satu sama lain. Dalam proses pembelajaran Bahasa Indonesia bagi Penutur Asing, pembelajran budaya biasanya diajarkan dalam kelas diskusi atau diselipkan pada materi ajar yang berkaitan. Salah satu yang termasuk budaya adalah bagaimana orang - orang dari suatu suku membuat satu standar atau patokan dalam menjalani hidup mereka. Sebut saja saat akan memilih pemimpin, ada tiga tolok ukur yang ditunjukkan dalam perspektif orang Bugis. termasuk tegas, jujur dan kata yang benar. Ketiga nilai itu benar-benar bertentangan dengan kasus-kasus yang terjadi dalam cerita novel Animal Farm karya George Orwell.

\section{REFERENCES}

[1] D. M. Gajewski, "Evaluasi Program Pengajaran BIPA- Suatu Perspektif Pelajar Asing," Saga, pp. 327-334, 2018.

[2] Husamah, "Mengusung Kembali Khazanah Identitas Budaya Bangsa.” P. 17.

[3] Khaerudin Kurniawan, "Menjadikan Bahasa Indonesia Yang Bermartabat Dan Jati Diri Bangsa," no. 1, pp. 1-13, 1976.

[4] A. H. Machmud, Silasa, Setetes Embun di Tanah Gersang, 1st ed. Makassar, South Sulawesi Indonesia: Pustaka Sawerigading, 2015.

[5] G. Orwell, "Animal Farm: A Fairy Story,” p. 144, 1945.

[6] Ruskhan Gaffar Abdul, "Pemanfaatan Keberagaman Budaya Indonesia Dalam Pengajaran Bahasa Indonesia," Semin. Pengajaran Bhs. Indones. Pertem. Asos. Jepang- Indones. di Nanzan Gakuen Train. Cent., no. November, pp. 1-4, 2007.

[7] Rohimah, "Internasionalisasi Bahasa Indonesia Dan Internalisasi Budaya Indonesia Melalui Bahasa Indonesia Bagi Penutur Asing (Bipa),” J. Hum., vol. 2, no. 2, pp. 199-211, 2018.

[8] P. Jim Ryeo, "Daya Literasi Pengajar Bahasa Indonesia Bagi Penutur Asing,” Pp. 12-28, 2019.

[9] I. Suyitno, "Pengembangan Bahan Ajar Bahasa Indonesia untuk Penutur Asing (BIPA) berdasarkan Hasil Analisis Kebutuhan Belajar," Wacana, J. Humanit. Indones., vol. 9, no. 1, p. 62, 2007.

[10] A. H. Tupan, "Pengembangan Bahan Ajar Bipa Melalui Materi Otentik Yang Bermuatan Budaya Indonesia,” J. Chem. Inf. Model., vol. 53, no. 9, pp. 1689-1699, 2019.

[11] A. Ulumuddin, Arisul ; Wismanto, “Vol. 2 No. 1 Januari 2014,” vol. 2, no. 1, pp. 1$14,2014$.

[12] H. Widyastuti, "Pemanfaatan cerita tradisi lisan untuk pengajaran bipa," no. November, pp. 1151-1166, 2017.

[13] K. Saddhono, "Cultural and Social Change of Foreign Students in Indonesia: The Influence of Javanese Culture in Teaching Indonesian to Speakers of Other Languages (TISOL)," in IOP Conference Series: Earth and Environmental Science, 2018, vol. 126, no. 1.

[14] K. Saddhono, "Integrating culture in Indonesian language learning for foreign speakers at Indonesian universities,” J. Lang. Lit., vol. 6, no. 2, 2015. 